\title{
O DIREITO ENTRE A CRISE ECONÔMICA E AS MANIFESTAÇÕES POPULARES: UMA INTERPRETAÇÃO À LUZ DE JESSOP E INNERARITY
}

\section{LAW BETWEEN ECONOMIC CRISIS AND DEMONSTRATIONS: AN INTERPRETATION ACCORDING TO JESSOP AND INNERARITY}

${ }^{1}$ Raquel de Mattos Pimenta

\section{RESUMO}

O presente artigo visa discutir o descompasso entre a produção do direito e as fontes de poder e legitimidade na sociedade contemporânea, a partir das transformações apontadas, na economia política por Bob Jessope no sistema político contemporâneo, por Daniel Innerarity. A transformação do Estado, para Jessop, explicada pelos processos de desnacionalização, desestatização e internacionalização e, para Innerarity, relacionada ao fim do sistema político como condutor da vida social, tem impacto sobre a produção do conhecimento e sobre a prática jurídica. Partindo da reflexão de Faria (2010), o artigo a ponta nove tendências para o direito contemporâneo, entre a crise e conômica e a crise política, apontando implicações da conjuntura atual, econômica e política, ao arcabouço jurídico.

Palavras-chave: Direito e conjuntura, Transformação do estado, Jessop, Innerarity

\begin{abstract}
This article aims to discuss the mismatch between legal knowledge and the sources of power and legitimacy in the contemporary society, departing from the transformations in the political economy appointed by Bob Jessop and in the political system, by Daniel Innerarity. The States transformation, for Jessop, is explained by the processes of denationalization, privatization and internationalization. For Innerarity, it is relatedto the end of the political system as a conductor of social life. Both phenomena impactlegal knowledge and practice. From the standpoint presented by Faria, this article reviews nine tendencies for contemporary law, between economic and political crises, explaining the consequences of conjunctural analysis for legal framework.
\end{abstract}

Keywords: Law and conjucture, State transformation, Jessop, Innerarity

\footnotetext{
${ }^{1}$ Doutoranda em Direito Econômico e Financeiro, pela Universidade de São Paulo, USP - SP, (Brasil). E-mail: raquel.pimenta@usp.br
} 


\section{INTRODUÇÃO}

Em 4 de dezembro de 2013, a Câmara dos Deputados aprovou proposta de emenda constitucional (PEC 90/2011) que torna o transporte um direito social, alterando a redação do artigo $6^{\circ}$ da Constituição Federal. Segundo sua autora (Dep. Luiza Erundina PSB-SP) e o relator (Dep. Nilmário Miranda PT-MG), a tramitação foi acelerada após as manifestações populares de junho de $2013^{1}$, as primeiras que encadearam diversas demonstrações no Brasil e que tiveram como estopim o aumento das passagens de transporte coletivo em diversas regiões do Brasil.

Diante do fato acima, algum leitor apressado diria que a política e o arcabouço jurídico, em sua mais alta expressão, a Constituição Federal, são constantemente mobilizados para dar respostas às manifestações populares, como as ocorridas em Junho de 2013, e o fizeram de forma adequada. As manifestações, no contexto de uma crise mundial e após a insurreição da sociedade civil em outros países como Estados Unidos da América e Espanha, seriam assim, mais cedo ou mais tarde, adequadamente processadas pelos poderes vigentes e por suas expressões jurídicas. Não haveria nada novo no horizonte.

O presente artigo vai de encontro a tal visão simplista. A partir das leituras dos artigos "La política después de la indignación" (2011) e "La transformáccion de la política para gobernar una sociedade compleja" (2011) de Daniel Innerarity e dos artigos "Narrating the future of the national economy and the national state? Remarks on remapping regulation and reinventing governance" (1999) e "The European Union and Recent Transformations in Statehood" (2004) de Bob Jessop, complementados com outros trabalhos, o estudo pretende apontar implicações da conjuntura atual, econômica e política, ao arcabouço jurídico, entendido como as normas, suas interações, instituições, e ao ensino jurídico. O objetivo do artigo é, por meio das interpretações de Jessop e Innerarity, demonstrar o descompasso entre a produção do direito e as fontes de poder e legitimidade na sociedade contemporânea.

Está organizado da seguinte forma: Primeiro, são apresentadas as principais ideias dos artigos de Bob Jessop. A análise do autor, calcada na economia política, aponta a erosão do Estado Nacional Keynesiano de Bem-Estar, por meio de processos de desnacionalização, desestatização e internacionalização e o surgimento de um novo regime de Estado, chamado Schumpeteriano, voltado à competitividade internacional e à meta governança.

\footnotetext{
${ }^{1}$ http://oglobo.globo.com/pais/camara-aprova-pec-que-transforma-transporte-em-direito-social-10972144
} 
Em seguida, é explicado o diagnóstico de Daniel Innerarity, sobre o fim o papel do Estado, no sentido específico de fim da imposição do sistema político como uniformizador e condutor de sociedade com sistemas funcionais diferenciados. Neste contexto, apresenta a tensão do sistema político entre instituições e "a rua", descompasso comum em revoltas populares e manifestações recentes de diversos países.

Depois, o artigo aponta mudanças constitutivas nas fontes de poder e no arcabouço jurídico decorrentes de a nova configuração da sociedade e do Estado apontada pelos autores.

Para tanto, toma por base o livro "Direito e Conjuntura" de José Eduardo Faria (2010), em especial, as nove tendências desenvolvidas pelo autor. Por fim, conclui.

\section{BOB JESSOPE AS TRANSFORMAÇÕES DO ESTADO}

Bob Jessop, nos dois mencionados, reconstrói as principais características do Estado Nacional do Pós Guerra e sua subsequente erosão a partir da metade dos anos 70, acelerada nos anos 1980 e seguintes. O chamado Estado Nacional Keynesiano de Bem-Estar (livre tradução de "keynesian welfare national state" daqui em diante referido como KWNS) passou por reorganização estrutural e reorientação estratégica em três frentes: desnacionalização, desestatização e internacionalização (JESSOP, 1999, p. 3).

Antes de passar à mutação do Estado, vale pincelar algumas características do KWNS ressaltadas por Jessop. Após a segunda-guerra mundial e diante do processo de consolidação do chamado Fordismo Atlântico, o Estado nacional foi fortalecido como espaço de economia e produção nacional, destinado ao bem-estar de população circunscrita ao território nacional. estado soberano era visto como principal ator no cenário político, sendo as instâncias subnacionais (como estados e municípios) meras reprodutoras de políticas econômicas e sociais formuladas no epicentro do poder. As diferenças regionais eram, em larga medida, desconsideradas nos planejamentos econômicos estatais que pretendiam dirigir a atividade econômica. Da mesma forma, a economia internacional era limitada ao fluxo comercial e financeiro entre Estados soberanos e não ocupavam o centro da preocupação de crescimento ou desenvolvimento ${ }^{2}$.

\footnotetext{
2 É justamente neste cenário que se fortalecem, na América Latina e em outros países, a Política de Substituição de Importação, focada no desenvolvimento de parque industrial e mercado consumidor internos e limitados aos contornos do estado nação. Sobre a Política de Substituição de Importação vide TAVARES, 2000.
} 
As políticas do Estado centravam-se na noção de lar constituído por uma figura materna e outra paterna, sendo este o responsável pela renda familiar. Os indivíduos esperavam certa estabilidade em sua renda, em parte conferida por sua associação a redes de proteção conferidas por organizações como sindicatos, associações comerciais ou outras.

Em síntese, Jessop aponta a relação estreita e retroalimentadora entre o Estado nacional e o keynesianismo de bem-estar. A partir da metade dos anos 1970, a narrativa do Estado nacional passou a apresentar mudanças. O diagnóstico que o Estado moderno já não mais cumpria suas funções misturava-se à crise do KWNS. Após tentativas pontuais de reformas, as atenções se voltaram à emergência de novo paradigma qualitativo de estado e sua inserção no sistema político. Jessop $(1999$, p.5) apresenta algumas características da crise orgânica e não transitória do KWNS.

Primeiro, a centralidade da soberania do Estado foi questionada, tanto pela crise de legitimidade que se instaurou perante a incapacidade do Estado de promover pleno emprego e crescimento econômico, bem como pela crise fiscal que paralisou a possibilidade de expansão das atividades do Estado. Tais crises foram aprofundadas pelas disputas com poderes locais ou regionais. Os problemas de localidades específicas não poderiam ser resolvidos por meio de política central ou uniforme.

A internacionalização crescente da economia rompia a ideia corriqueira que os objetivos econômicos se circunscreviam à economia nacional. Ademais, como produto da internacionalização, diversos países centrais passaram a aceitar trabalhadores de antigas colônias, para conciliar a necessidade do fordismo de trabalho barato para fomento da economia de bem-estar. Tal levou à crescente tensão entre grupos étnicos e culturais distintos, ao exacerbamento de identidades culturais e declínio da unidade étnica dos países centrais. O Estado passava a ter que dar conta não só da população circunscrita ao seu território, mas também dos fluxos migratórios. Outro fator desestabilizador foi a reinvenção dos laços afetivos familiares, a feminização do trabalho pago e o surgimento de desemprego a longo prazo (bem como desemprego estrutural). Todas as mudanças acima são potencializadas pela crise da representatividade política baseada em organizações do tipo partido e sindicato e a emergência de novos movimentos sociais.

Para resolver as contradições profundas e problemas do KWNS, há busca generalizada por novas formas de Estado. Jessop (1999 e 2004) discute a emergência de novo regime Estado por meio da transformação estrutural - desnacionalização e desestatização - e 
reorientação estratégica - internacionalização - do antigo KWNS. Tais processos estão relacionados à rearticulação e remapeamento da base territorial e funcional do Estado nacional do pós guerra, em direção a Estado Schumpeteriano (Schupeterian Workfare Regime).

A rearticulação das diversas funções do Estado passa, inicialmente, pela desnacionalização do Estado por dois movimentos distintos e complementares: perda de autonomia frente a espaços de coordenação supranacionais e insurgência das localidades como competentes para lidar com problemas específicos. A emergência de relações translocais também aprofunda o fenômeno.

Primeiro, a expansão do número e escopo de regimes políticos internacionais (como é o caso da União Europeia) aumentou sua complexidade (Jessop, 2004). A preocupação com a competitividade internacional dos países ultrapassou o domínio clássico dos fluxos comerciais ou de investimento externo, deslocando a referência da economia interna para a economia internacional. Depois, a emergência de governanças locais e regionais como aptas a formularem políticas públicas que dão conta das especificidades locais e, ao mesmo tempo, atendem aos imperativos da competitividade internacional (com o desenvolvimento de infraestrutura e recursos humanos) deslocou diversas competências do nível nacional para subníveis regionais e locais. Por fim, a possibilidade de parcerias das sub-regiões ou localidades com parceiros internacionais sem a intermediação do Estado nacional aprofundou a desnacionalização do Estado.

O segundo processo de rearticulação das funções do Estado se deu pela desestatização da política, ou seja, pelo abandono da centralidade do governo em direção a formas descentralizadas de governança, em todos os níveis (supranacional, nacional e subnacional). Trata-se da formação de redes sob formas variadas de parceria entre Estado, organização não governamentais e paraestatais para administrar relações econômicas e sociais, em detrimento de modelo vertical hierarquizado, centralizado e dirigista. O Estado não mais coordena as relações econômico e sociais por cima, mas se engaja em negociações reflexivas, interdependentes e de aprendizado mútuo. Altera-se, portanto, a linha divisória entre público e privado (Jessop, 2004, p. 4), bem como as atribuições concedidas a cada uma dessas instâncias.

Em terceiro, a internacionalização dos regimes de políticas públicas altera orientações estratégicas do Estado e a importância de fontes internacionais de políticas. Como comentado acima, o objeto central dos Estados deixa de ser a economia nacional para ser a competitividade internacional, noção em termos amplos. A competitividade internacional envolve a promoção de inovação em produtos, processos e organizações em economia aberta 
para fortalecer, ao máximo, a competitividade estrutural da economia, intervindo, sobretudo, no lado da demanda. Diferentemente do KWNS, na nova configuração schumpeteriana, políticas de pleno emprego dão lugar a políticas de competitividade, direitos relacionados ao bem-estar social são colocados em segundo plano vis-à-vis a reorganização produtiva de políticas sociais e cresce o papel da governança multifacetada, em detrimento do estado nacional e central.

Por fim, Jessop (2004, p.5) ressalta que a desnacionalização, desestatização, internacionalização não torna os Estados prescindíveis. Tais fenômenos representam o esfacelamento da unidade que marcou o KWNS e a reorganização funcional e estratégica do Estado ao redor de outros centros de gravidade. O Estado torna-se guardião da metagovernança, ou seja, se envolve para facilitar o aprendizado coletivo entre diferentes locais e diferentes ações (Jessop, 2004, p.6), promovendo flexibilidade necessária para o objetivo de competitividade internacional. Trata-se de metagovernança por conformar o desenho de métodos de coordenação, aprimorando seu desempenho em ambiente cambiável. A metagovernança não atua em ambiente de estabilidade absoluta, que caracterizava o KWNS, mas com processos e interdependências que podem se alterar e desequilibrar compromissos anteriores.

A crise econômica iniciada nos Estados Unidos com efeitos mundiais é resultado de diversos fatores e seus desdobramentos revelam o distanciamento cada vez maior do Estado Schumpeteriano com o Estado Nacional Keynesiano de Bem-estar. A especialização funcional do sistema econômico produziu, nas últimas décadas, o desenvolvimento acelerado de inovações financeiras, sobretudo de derivativos e arbitragens com taxa de câmbio e juros, muitas vezes por meio de operações realizadas em ambientes não regulados ou opacos ao regulador (FARIA, 2012).

Mais especificamente, o mercado hipotecário subprime americano apresentou grandes taxas de crescimento, tanto pela valorização de imóveis quanto pelo surgimento de instrumentos financeiros que permitiam a transferência do risco de inadimplemento a terceiros, por meio de instrumentos de securitização. Tais produtos novos e complexos, muitas vezes não tinham regulamentação adequada (YAZBEK, 2009), que se espalharam rapidamente pela carteira de instituições financeiras diversas, em diversos países. Os valores mobiliários decorrentes de tais operações recebiam avaliações positivas de agencias de ratings, o que contribuiu para sua pulverização em níveis e âmbitos diversos. Com o desaquecimento da economia americana, os índices de inadimplemento de hipotecas que constituíam a base de tais valores cresceram. Todos os instrumentos construídos sobre tais bases passaram a falhar ou gerar 
grandes prejuízos. Como títulos podres estavam presentes em carteiras de instituições financeiras diversas, uma crise de grandes proporções foi precipitada.

Até a metade de 2008, os sinais da crise foram pontuais e contornados por tendências de concentração incentivadas pelos reguladores estatais. O Bearn Stearns, até então poderoso banco de investimentos americano, foi vendido ao JP Morgan Chase. O Merrill Lynch foi adquirido pelo Bank of America e o Nothern Rock no Reino Unido foi nacionalizado. No entanto, o aprofundamento da crise é marcado em setembro de 2008 pela quebra do Lehman Brothers, banco de investimento emissor de produtos financeiros negociados em todo o mundo. A partir deste momento, a instabilidade financeira tomou grandes proporções, espalhando-se, inclusive, para a economia real. Estima-se que a crise gerou perdas de $25 \%$ da riqueza mundial (FARIA, 2012, p. 26). A crise econômica retrata de forma aguda, a internacionalização e interconexão dos capitais (sobretudo do capital financeiro) e a relativa debilidade das funções e ações tradicionais do Estado Keynesiano (desnacionalização e desestatização) frente a tais novos desafios, sendo a modelagem clássica incapaz de antever, prevenir e até mesmo de intervir na crise que avassalou o mundo.

\section{INNERARITYE O PAPEL DA POLÍTICA}

Como visto acima, Jessop baseia-se em análise de economia política para compreender o fenômeno da passagem do Estado Nacional Keynesiano de Bem-Estar para Estado Pós Nacional Schumpeteriano. A análise de Innerarity concentra-se na transformação do papel e proeminência da política nas sociedades contemporâneas. Em perspectiva distinta, com outro instrumental, Innerarity complementa a análise de Jessop a partir de uma leitura de teoria dos sistemas. O presente item desenvolve suas ideias.

Para Innerarity e para a teoria dos sistemas de uma forma geral, as sociedades contemporâneas em países avançados seriam funcionalmente diferenciadas e cada sistema que se encarregasse uma função (política, direito, economia, arte, religião), manteria lógica e coerência autônoma, sem intromissão ou preponderância de um sistema pelo outro. A complexidade contemporânea está relacionada à diversificação dos centros de decisão que cada sistema possui, sem controle hierárquico por nenhum deles (2011a, p. 233). Trata-se de uma concepção social inédita: A Constituição Federal ou o sistema político não poderiam pretender exercer papel de uniformizador e ordenador dos sistemas, buscando se sobrepor e dirigir os demais por meio da hierarquia. Para Innerarity, a política (e seu locus de exercício, o Estado) se tornaria ultraexigida e hiperativa se tentasse se impor sobre todos os demais sistemas. 
Innerarity explora como a ideia de hierarquia encontra-se esgotada nas sociedades contemporâneas (2011a). A unidade da sociedade não é dada por um único sistema, como sistema político e sua lógica de poder, mas pela dependência recíproca entre sistemas especializados e autônomos. A sociedade contemporânea é submetida à dinâmica centrífuga destes sistemas, em que cada qual opera conforma a própria lógica e gera superprodução de possibilidades sobre eles mesmos. Não podem ser controlados ou coordenados centralmente porque cada sistema obedece a um tipo de linguagem. A coordenação para estabelecer equilíbrio entre os sistemas é de difícil implementação, uma vez que cada um opera em um mundo comunicativo próprio, de acordo com as suas regras de constituição e desenvolvimento.

Neste panorama, caberia ao sistema político a função de mediação social com abandono do vértice hierárquico. A hierarquia traria simplificações excessivas e desnecessárias para o funcionamento de cada sistema e acabaria por reduzi-los. A política, então, para Innerarity, deveria frear a dinâmica centrífuga dos sistemas sociais autônomos por meio de supervisão, abandonando a ideia artificial de unidade. O sistema político sensibilizaria e fortaleceria a capacidade de reflexão e reorganização de cada sistema, auxiliando sua compatibilidade e a autorganização.

Tal ação implicaria na autolimitação da política sobre seu espaço de atuação. Isso passaria pela consecução de novo equilíbrio entre tarefas públicas e privadas, com a retirada da política em âmbitos em que apenas reforça a incompetência e sobrecarga (Innerarity, 2011a, p.241). As intervenções típicas de bem-estar devem se auto limitar de forma ativa e autoreflexiva: retirando-se de âmbitos como a família, a cultura e educação, todas esferas que obedecem à lógica de outros sistemas. A autolimitação não é fenômeno novo: a autonomia conferida a Bancos Centrais, Universidades, a ideia de federalismo e o princípio da subsidiariedade são restrições artificiais impostas pelo próprio sistema político, ao seu próprio

exercício. A revisão das tarefas do Estado partiria de mudanças deste gênero, considerando sua retração substancial e reformulação.

Para Innerarity (2011a), o Estado planificador infringe a complexidade e dinâmica de processos sociais naturais de outros sistemas, com intervenções difíceis, pois hoje se depara com objetivos rebeldes, meios contraditórios e causas discontínuas, gerando resultados incertos. A solução não residiria no arcabouço teórico do Estado mínimo, que não reflete sobre a sociedade desejada, focando-se excessivamente no indivíduo. Os sistemas funcionais e autônomos ultrapassam a esfera do indivíduo e as concepções atomizadas de espaço social. 
O governo deve se prepara para ser contextual, heterárquico e discursivo (Innerarity, 2011a ). Deve atuar como moderador social de processos de aprendizagem, com abandono da pretensão de respostas corretas e o reconhecimento da interdependência dos sistemas.

Portanto, a política deve estar apta a entender estratégias de autogoverno. Isto não significa passividade frente a eventuais irracionalidades ou tragédias dos sistemas, mas a flexibilização das estratégias para atingir e corrigir caminho, por meio de controles próprios e internos a cada sistema. Significa renunciar a construções externas que anulam a pluralidade e a riqueza de opções que cada sistema produz em si mesmo. Cabe à política, segundo o autor, moderar negociações e estabilizar formas de cooperação entre sistemas, para que os atores das redes de mediação e cooperação possam assumir riscos. Deve, no entanto, se furtar à imposição de solução top down ou recorrer a formas de intervenção direta.

O novo papel do Estado e da política é, precisamente, atuar como supervisor, criando condições para cooperação para que cada sistema possa romper sua autor e ferencialidade estrita (Innerarity, 2011a). A cooperação permite que o sistema se torne compreensível a outros para obter informações de outros sistemas, permitindo que a auto composição entre sistemas os torne compatíveis reciprocamente. A supervisão aumenta a capacidade de observação dos sistemas e diminui seus pontos de cegueira, incrementando sua práxis social.

A operacionalização da supervisão é um procedimento discursivo que submete a possibilidade de estabelecer condições contextuais comuns entre sistemas sem intervenção externa. No limite, a supervisão representa a experimentação de realidades hipotéticas.

O governo então, não se enxerga mais como marco de condições para a sintonia entre os sistemas. Se entende apenas como parte da constelação entre sistemas, sem força ou competência para se sobrepor aos demais. O governo descentralizado abandona a ilusão de salvador de última instância. A visão de Innerarity complementa o diagnóstico de Jessop sobre as mutações do Estado e sua nova arquitetura funcional e estratégica.

Tratando mais especificamente da política diante dos protestos espanhóis, Innerarity tenta desvendar o significado da política para os chamados "indignados" (2011b). De acordo com o autor, a função dos protestos é manifestar mal-estar dos cidadãos e sua exigência frente aos governos. Não possui ação coesa ou programa esquematizado, porque não visa a mudanças radicais, mas tão somente dar vazão a um tipo de expressão. Isto porque, em linha com o que argumentou, Innerarity não vê mais a política como espaço para produção das grandes mudanças almejadas por este mal-estar compartilhado entre atores sociais (2011b). 
Na democracia, existe uma tensão permanente entre instituições e a rua, que produz síntese benéfica. A democracia abarca tais tensões porque se funda em dualismo equilibrado entre instituição e rua, bem como entre obediência versus protesto e representação versus participação. Se por um lado, é verdade que as conquistas sociais são fruto de pressões específicas, originadas nas "ruas", por outro, nem sempre a rua produz forças progressistas.

Ao contrário, muitas vezes podem produzir forças retrógradas, que espelham a pluralidade e vitalidade da vida social. Para evitar retrocessos, as instituições servem como contrapeso que protegem a sociedade de demagogias de invocação ao povo. Na contramão de certa exaltação à espontaneidade e aos movimentos de rua, Innerarity (2001b) lembra que as instituições reconhecem a pluralidade constitutiva e a complexidade da vontade do povo e que quem protesta nem sempre tem razão ou aspirações mais democráticas.

Neste sentido, o autor faz uma crítica à utopia da desintermediação muito em voga nas análises e práticas dos movimentos populares contemporâneos. As redes sociais, a participação online tem propagado a ideia que de a mediação da vontade, feita essencialmente pela classe política, seria mais opaca, oblíqua e ilegítima. Tal forma de pensar advém dos novos paradigmas tecnológicos, sobretudo a internet, que transformam as noções de espaço público e as relações com as autoridades. Isto porque a tecnologia permite a desintermediação da informação, levando à consagração do amador, aquele que se informa sozinho e expressa suas opiniões. $\mathrm{O}$ saber deixa de ser poder exotérico para se democratizar.

A utopia de abolir a mediação produz movimentos ambíguos: se por um lado parece corresponder ao sonho democrático de espontaneidade, transparência e reconhecimento da vontade política, por outro, gera espaço público sem contralimites (garantia de direitos), procedimentos (freio à arbitrariedade) e representação (freio ao populismo), fatores que protegem a democracia dela mesma. Evocar uma política que produza a "verdadeira realidade social" pode perigosamente servir de justificativa para qualquer coisa.

Para Innerarity, o desafio da política não é desconstruir as instituições, mas sim arquitetar formas menos rígidas de mediação, que proteja direitos e corrija efeitos não desejados (2011b). A sociedade democraticamente madura é aquela em que a experiência política pode ser decepcionante, mas com exigência cada vez maior sobre ela. Quem toma problemas da vida social como questões de princípio irrenunciáveis se frusta com a capacidade do sistema político de acomodar e encontrar soluções de compromisso. No entanto, é justamente essa capacidade de conformação o que constitui o pilar da política, explicitando que o poder é uma realidade compartilhada. 
Uma sociedade heterarquicamente organizada tende a destotalizar a política, porque o espaço público já não absorve todas as dimensões da subjetividade. Há portanto a dessacralização da política, como apenas mais um dos sistemas sociais. A vontade geral em sociedades complexas é um compromisso entre diferentes, para tanto, a representação confere a possibilidade do governo se distanciar dos eleitores para desvincular-se do instante das pressões populistas. Isto sempre sob a possibilidade de substituição do governo ao término do mandato. As eleições são então o que rompem a inércia desta separação, confirmando a promessa de autogoverno e agindo para prestação de contas e cobrança de respostas.

Alguns movimentos populares e protestos contemporâneos negam o benefício da representação política como lugar do compromisso e mediação, ou da paridade regional. Mais importante, não percebem que a representação política é um esforço permanente de síntese, no qual a sociedade ganha distância de si mesma, permitindo a análise de suas práticas, elaborando, assim, intepretações comuns da convivência. Na visão de Innerarity (2011b), a indignação é virtude cívica, mas insuficiente para aprofundamento da representação, sem cair na crítica fácil e simplificadora de sua realidade.

\section{OS MÚLTIPLOS DESAFIOS PARA O DIREITO}

Em sociedade com sistemas funcionais diferenciados que paulatinamente viu erodir o paradigma do KWNS em favor da multiplicação de stakeholders, centros decisórios subnacionais e internacionais, inserida no objetivo de competitividade internacional como chave de mobilização da ação do Estado, o Direito passa por grandes desafios e transmutações.

Se o Estado soberano e nacional é enfraquecido diante de outros atores locais e transnacionais, sua expressão normativa, o direito positivo também passa por abalos sísmicos.

Se as regras são pensadas para contextos estáveis, como lidar com realidades complexas e arranjos provisórios entre múltiplos agentes? Se as noções de "interesse público" e "bem público" não são mais capazes de fornecer sentido único e ordenador para sistemas funcionais especializados, como padronizar expectativas e criar instituições duradouras de coordenação e convergência? Se a linha entre função pública e função privada se alterou como estabelecer regimes diferenciados (como era o regime de direito público e o regime de direito privado)?

Se a representação política é posta em cheque, como pensar em regras gerais e abstratas que abarquem os interesses conflitantes postos na sociedade? 
A emergência de um novo Estado, com novas funções e novos centros de produção normativa aumentam a complexidade do sistema jurídico. As normatividades são formuladas conforme a lógica de cada sistema ou subsistema, em contextos de constante interação entre a esfera nacional e internacional, fragmentando e pulverizando a produção normativa.

Para Faria (2010) as novas formas e funções do direito podem ser sintetizadas em nove tendências. A primeira diz respeito ao alargamento e desformalização dos procedimentos de elaboração legislativa, permitindo que setores especializados, especialmente aqueles de alta complexidade técnica, possam intervir na elaboração de decisões normativas. Multiplicam-se técnicas de consulta pública, painéis de discussão e diálogo com especialistas no Legislativo, Executivo e até mesmo no Judiciário, com a figura do amicus curiae. São figuras que permitem forjar consensos e evitar desgastes políticos, possivelmente aprofundando mecanismos de participação democrática. Contudo, geram o risco de captura das autoridades por interesses representados. Para o autor, tais interações na elaboração de normas e decisões permite processo de aprendizagem baseado em experimentações, de contínuo ajustamento das leis à realidade - o que contém o risco de apropriação de tais experimentos por experts ou descambar em processo de contínua improvisação.

A segunda tendência, segundo o autor, é a paulatina diminuição da imperatividade do direito positivo. Com os processos de desestatização, seguidos por deslegalização e até desconstituicionalização, abdica-se do direito positivo em favor de soluções heterônimas e práticas flexíveis de enquadramento do comportamento. A lei passa a criar espaços para decisões, entendimentos e engajamentos - expressa em princípios, códigos de conduta e diretivas. Reconhece-se, portanto, a autonomia decisórias dos sistemas sociais e abdica-se de normas pretensamente universais e hierárquicas. Tal não representa menor coercibilidade das normas, mas seu jogo com as instâncias privadas e com os contextos.

A terceira tendência está relacionada a diminuição do formalismo dos tribunais e dos mecanismos processuais. Para Faria (2010), diante da alteração da concepção do tempo em mercados transnacionais, o processo decisório fora dos tribunais tornou-se praticamente instantâneo. A concepção garantista de tempo nos tribunais tornou-se antiquada e penosa, criticada por organismos de crédito e muitas vezes neutralizada pela mediação e arbitragem.

A quarta tendência está relacionada à dolarização do conhecimento jurídico, com a influência crescente da hegemonia inglesa e americana sobre as finanças mundializadas. A expansão de padrões legais do sistema da common law invade as mais diferentes áreas do direito, de processo a antitruste, de societário a penal, de terceito setor à propriedade intelectual. Muitas 
vezes tal padronização foi patrocinada por organismos multilaterais, que acreditaram em seu caráter universal, independente das práticas sociais de cada país ou contexto.

A quinta tendência representa a expansão dos campos de contratualização, de espaços de liberdade juridicamente criados para que os próprios agentes criem seu direito, como fonte normativa flexível. O resgate do contrato como fonte normativa vem acompanhado da relativização da distinção entre direito provado e direito público para abrir espaço aos policontextos normativos.

Para Faria, a sexta tendência seria o enfraquecimento do direito do trabalho, obrigado a lidar com formas variáveis de novos sistemas de organização da produção, de difícil padronização. Em contexto de volatilidade dos capitais, combinada com o avanço da terceirização e precarização do trabalho, o caráter estatutário e estável do Direito do Trabalho passa a ser contornado por formas que buscam desonerar agentes produtivos, por meio de sistema negociado entre partes.

A sétima tendência apontada por Faria é a de refundação do direito internacional, sob a fragmentação e especialização entre as diversas matérias, bem como o surgimento de ordenamentos regionais. Seu mecanismo passa a se centrar em resolução de disputas específicas, que levam a soluções divergentes - e minam a credibilidade do Direito Internacional (Faria, 2011, p. 101). A legitimidade do Direito Internacional não decorre mais apenas da negociação entre Estados, mas também por agentes transnacionais como empresas, ONGs e outros.

A oitava tendência é o aumento do ritmo de regressão dos direitos sociais e dos direitos humanos tutelados pelo direito positivo. Tais direitos dependem de uma grande capacidade de intervenção e financiamento do Estado, o que já não é mais possível em cenário de alta competitividade internacional e recursos escassos. No âmbito das políticas públicas, os direitos universais são substituídos por estratégias de focalização (transferência de rendas condicionadas, microcrédito) para reduzir dispêndios e acumular capital físico.

A última tendência do direito apresentada por Faria é o recrudescimento do direito penal, por meio de criminalização crescente das condutas, repressão de delitos com pequeno potencial ofensivo e rigor na aplicação de sanções. Tal seria consequência do desfacelamento do tecido social, o aumento da violência e a dificuldade do Estado para se impor em certos ambientes. 


\section{CONCLUSÃO}

Independentemente da consolidação ou não de tais tendências, elas demonstram que a conjuntura atual da sociedade e do Estado, sobre a qual o direito é produzido e reproduzido, vem sofrendo alterações profundas em sua fonte de poder e legitimidade, como apontadas por Jessop e Innerarity. O arcabouço jurídico já não se sustenta mais em uma concepção monista, piramidal e regrada (Faria, 2010). Ao contrário, assistimos à emergência de regimes diversos e sobrepostos, espalhados em espaços transnacionais e regionais, com múltiplos agentes envolvidos.

Neste sentido, a ciência e o ensino jurídico passam por transformações epistemológicas profundas. O ensino de um sistema jurídico hermético, centrado na rotina dos tribunais, sem preocupação com a legitimidade ou eficácia da norma posta ignora universos normativos distintos como instâncias internacionais, negociações intracorporações, órgãos quase-judicantes dentro do Estado e mecanismos de mediação e arbitragem. $\mathrm{O}$ foco no direito positivo sob uma dimensão essencialmente formalista explica apenas uma parcela da realidade do arcabouço normativo e não habilita os operadores e inventores do direito para realidades complexas e especializadas.

Se permanecer com suas formas prontas e com teorias imaginadas para a sociedade industrial (em contraposição à sociedade informacional que vivemos), o Direito permanecerá à margem ou à deriva da vida social, tornando-se técnica ultrapassada e a reboque das transformações. Portanto, as soluções como a PEC 90/2011 da introdução deste artigo, ou a inserção constitucional de um ou outro princípio na Constituição, revelam a paralisia do sistema jurídico e de seu ensino frente aos desafios da sociedade contemporânea, sem a reflexão do papel e alcance do direito frente as crises econômicas e as mudanças no bojo do Estado e do sistema político. Que tais fenômenos sirvam para reflexão aprofundada e para a busca de novos caminhos para o ensino, pesquisa e prática jurídica. 


\section{REFERÊNCIASBIBLIOGRÁFICAS}

FARIA, J.E. O Estado e o direito depois da crise. São Paulo: Saraiva, 2012.

SociologiaJurídica: Direito eConjuntura. São Paulo: Saraiva, 2010.

JESSOP, B. Narrating thefuture of national economy and national State? Remarks on remapping regulation and the reinventing governance. Em STEINMETZ, G. StateFormationAfterdeCultural Turn, CornellUniversityPress, 1999. p. 378-406.

.The European Unionand recent transformations in state hood. Em LATZER, Michael, MOKRE, Monica e RIEKMANN, S.M. Transformation of State hood from a European Perspective.Cambridge University Press, 2004. p. 75-94.

.The Return of the National State in the Current Crisis of World Market. Capital \&Class, vol. 34, n.1, 2010. p. 38-44.

INNERARITY, D. La democracia delconocimiento. Barcelona: Paidós, 2011a.

. La políticadespuésde laindignación. Madrid: Claves deRazón Práctica, 2011b, n.218

Quèés aixóde lagovernança? Revista VIA, Maio 2012, p. 41-51. Disponível em http://www.danielinnerarity.es/art\%C3\%ADculos último acesso em 17.ago.2015.

PEREIRA,P.C.Câmara aprova PEC que transforma transporte em direito social. O GLOBO. Disponível em http://oglobo.globo.com/pais/camara-aprova-pec-que-transforma-transporteem-direito-social-10972144 Acesso em 24.12.2013.

TAVARES, Maria da Conceição. Auge e Declínio do Processo de Substituição de Importações no Brasil. Em. Em BIELSCHOWSKY, Ricardo. Cinquenta Anos de Pensamento na CEPAL. Rio deJaneiro: EditoraRecord, 2000, vol.I.

YAZBEK, O.Regulação domercado financeiroe de capitais,2a.ed. ampliada, São Paulo, Elsevier, 2009, p. 175-182. 